\title{
Mass customization based on generic technology and modular production method
}

\author{
Chen Guojie $^{1, \mathrm{a}}$, Liu Xianhui ${ }^{1, \mathrm{~b} *}$, Zhao Weidong $^{1, \mathrm{c}}$ \\ ${ }^{1}$ School of Electronics and Information Engineering, Tongji University, Shanghai, China
}

\begin{abstract}
Mass customization combines mass production with personalized customization, which avoids high cost, limited batch and long delivery time in customized production, and low flexibility and poor market reaction ability in mass production. However, due to the customization of its production strategy, mass customization production has disadvantages in cost and time in the production process. Aiming to these problems, this paper studies the promoting role of generic technology and modular customization methods in mass customization production mode. Through modular organization, modular design, modular manufacturing and modular assembly in industrial chain resources, to maximizes production capacity and achieve the goal of reducing enterprise production costs and improving enterprise production efficiency.
\end{abstract}

\section{INTRODUCTION}

In 1987, Stanley Davis first proposed the concept of mass customization, pointing out that mass customization is a highly agile, flexible, and integrated manufacturing process. On the basis of maintaining the production benefits of economies of scale, it enables enterprises to produce products or services that meet the unique needs of customers in large quantities by manufacturing a single product, which not only meets the needs of customers for product differentiation. This production model not only meets the needs of customers for product differentiation, but also ensures high efficiency and low cost in production $^{[1]}$. In 1996, Hart gave an operational definition of mass customization, proposing that mass customization uses flexible processes and flexible organizational structures to provide diverse products and services. The prices of such products and services can compete with standard mass production.

Mass customization is a production method oriented to customer needs, supported by modern information technology and flexible manufacturing technology, based on modular design, standardization of parts and components, marked by agility, and by means of cooperation-competition supply chain management ${ }^{[2]}$, the production method of mass customization is shown in Figure 1. In addition, mass customization also requires dynamic manufacturing requirements, flexible resources, late design of product diversity, product family structure and flexible process paths. Gao Yun elaborates on mass customization from the following five aspects:(1) Products are diversified and personalized, customer satisfaction is high, and it has economies of scale; (2) Customized products or services have low cost and high quality; (3) Product development cycle and life cycle are relatively short; (4) It carries out flexible production based on modularity and standardization; (5) It is supported by modern information technology and can quickly respond to market demand ${ }^{[3]}$. Therefore, mass customization production requires advanced modern information technology, flexible manufacturing technology, highefficiency supply chain management mode and product design to meet market demand, which can greatly improve the market competitiveness of enterprises and become the main mode of future production for enterprises. It is also an inevitable trend. Based on this, this paper studies the promotion of the generalization of modern information technology and the role of modular production methods in promoting the development of mass customization. 


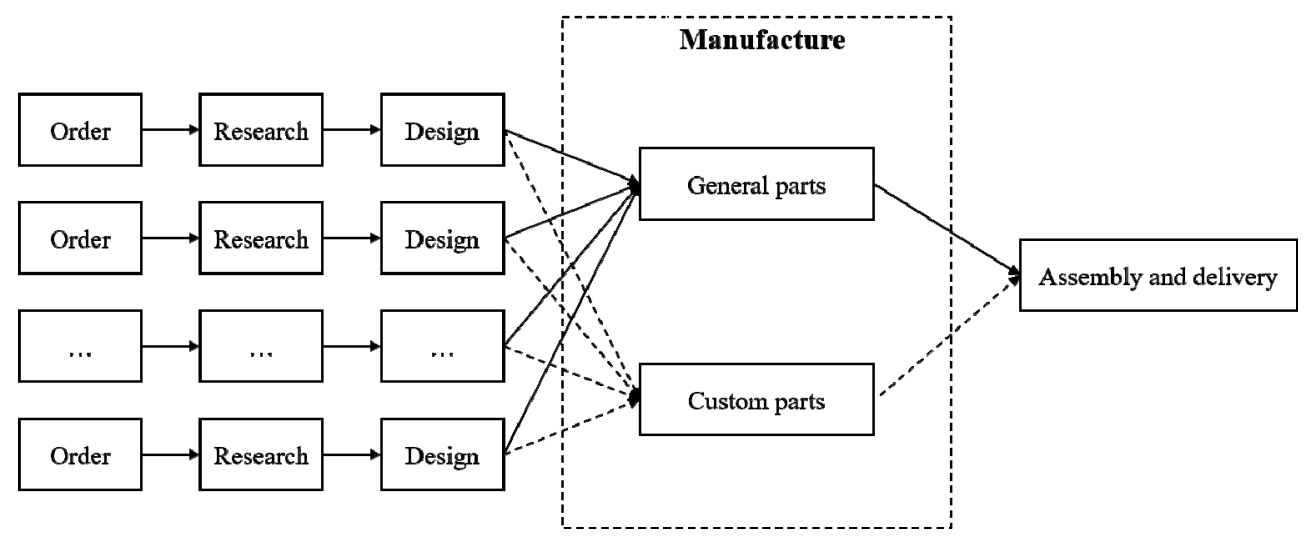

Figure 1. Mass customization

\section{MAss Customization Under Generic TECHNOLOGY}

Mass customization is a customized production method. Therefore, quickly and accurately understanding the individual needs of users and responding quickly and accurately to market changes is an important basis for mass customization. Mass customization emerged from modern information technology. The rapid development of modern information technology has provided a strong impetus for the generalization of mass customization production models. Through modern information technology, enterprises have reduced the economic cost and time cost required to obtain user personalized demand information, which enable enterprises to respond quickly and accurately to market changes based on the characteristics of user consumer psychology. Therefore, how to promote the innovation and development of modern information technology and improve the response speed of enterprises to the market is very important for the development of mass customization.

The current consensus reached by the academic community on common technologies is that they have been or may be widely adopted in many fields in the future, and their research and development can be shared and have a profound impact on one industry or multiple industries and enterprises. At the same time, it will play a rapid leading role in the entire industry or industrial technology level, industrial quality and production efficiency, and has huge economic and social benefits ${ }^{[4-5]}$, the potential value it contains is shown in Figure 2. Therefore, the commonality of modern information technology is an effective means to accelerate the innovation and development of modern information technology. Through the government's strategic and policy assistance in the common transformation of modern information technology within the enterprise, it will make enterprise enable to quickly obtain common technologies at a lower price that to guide the diffusion and transformation of common technology, coordinate and compensate the interests of the parties involved in cooperative development, and adopt a reasonable form of diffusion. On this basis, the development of competitive technologies and products in combination with market demand can achieve the purpose of promoting the overall progress of the industry, enhance the competitive advantage of the industry and promote the development of enterprise mass customization through the development of generic technologies.

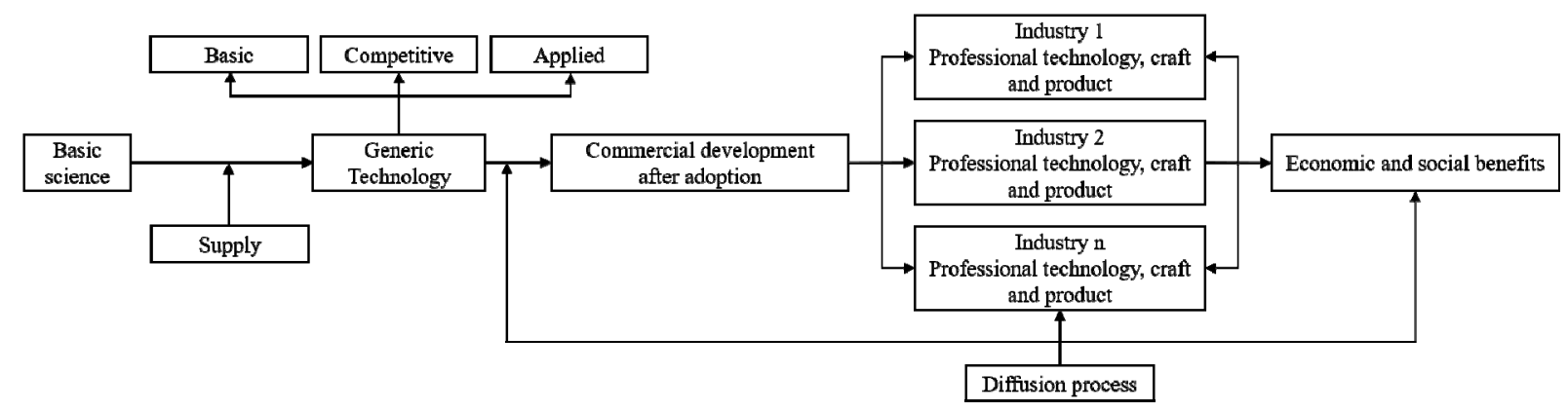

Figure 2. The potential value of generic technologies

\section{Mass Customization Unfer HyBRID Modularity}

As a new production technology, modular production can improve the utilization rate of resources and effectively avoid the waste of raw materials in the production process. On the other hand, it can promote the development rate of new products, shorten the development cycle, and simplify complex steps in the production process. Enterprises must control their standardization and standardization methods to greatly increase the success rate of mass customization production. Some parts can be converted into the end of other products through modular production, and in the process of customization, the quality of the product can be guaranteed, the quantity 
produced can meet the market demand, and the production speed will be improved [14-15]. Therefore, for modular production methods, the use of modular organization, modular design, modular manufacturing and modular assembly is the key to high-efficiency and low-cost production of mass customization.

1) Modular organization: Modular organization follows the principle of modular design. It has the characteristics of self-organization and self-learning within the modular, which is less restricted by the outside world and reduces the management level. At the strategic level, modular organization replaces strategic coordination with modular department integration. Through the introduction of market mechanism, it forms a relatively independent modular department within the enterprise, which makes the enterprise shift from traditional departmental incentives to high-energy market incentives. From the perspective of organizational governance, the modularized organizational system is more efficient than traditional bureaucratic organizations, and the loosely modularized organizational model can save the cost of supervision and negotiation of sub-parts.

2) Modular design: Modular design mainly refers to dividing the entire product or system design into many modules that are independent in function and complementary in performance according to certain rules. It can quickly form a variety of products by adjusting their order of composition to meet consumption Diversified needs. In the process of customized production, the degree of standardization of various modules and components is positively correlated with the level of modularity, which fully reflects the effect that mass customization enterprises can use modular design to achieve economies of scale.

3) Modular manufacturing: Modular production methods combine manufacturing networks and modular manufacturing, making full use of the advantages of the supply chain to implement modular manufacturing based on virtual enterprises, and meet specific market demand in time through module outsourcing or module supplier supply. Modular manufacturing with manufacturing network as the production organization model makes full use of external market resources, grasps market opportunities agilely and quickly, and achieves highquality, efficient, parallel production of modules through the combination of enterprises to meet customers with the shortest delivery time demand.

4) Modular assembly: Modular assembly is a more advanced product assembly method. It greatly shortens the total assembly time, simplifies the balance and optimization of the assembly line, improves the efficiency of the assembly line, and realizes the economies of scale of the assembly line. It is currently satisfying customers' diversification and individualization. Requirements and main assembly methods for low-cost and efficient production of mass customization.

For modular production methods, firstly, it divides the product into functional modules reasonably, use the similarity of modules to reduce changes in product structure and manufacturing structure, and use the choice of modules and the combination of modules to maintain product diversity and control product costs. Secondly, it penetrates the customer's individual needs into the product design stage. From the initial design stage to the final delivery stage, the entire production process reflects the customer's individual needs and greatly improves customer satisfaction. Finally, through modular manufacturing and modular assembly, the product life cycle and the time to market are shortened, so as to maximize production capacity, reduce enterprise production costs and improve enterprise production efficiency.

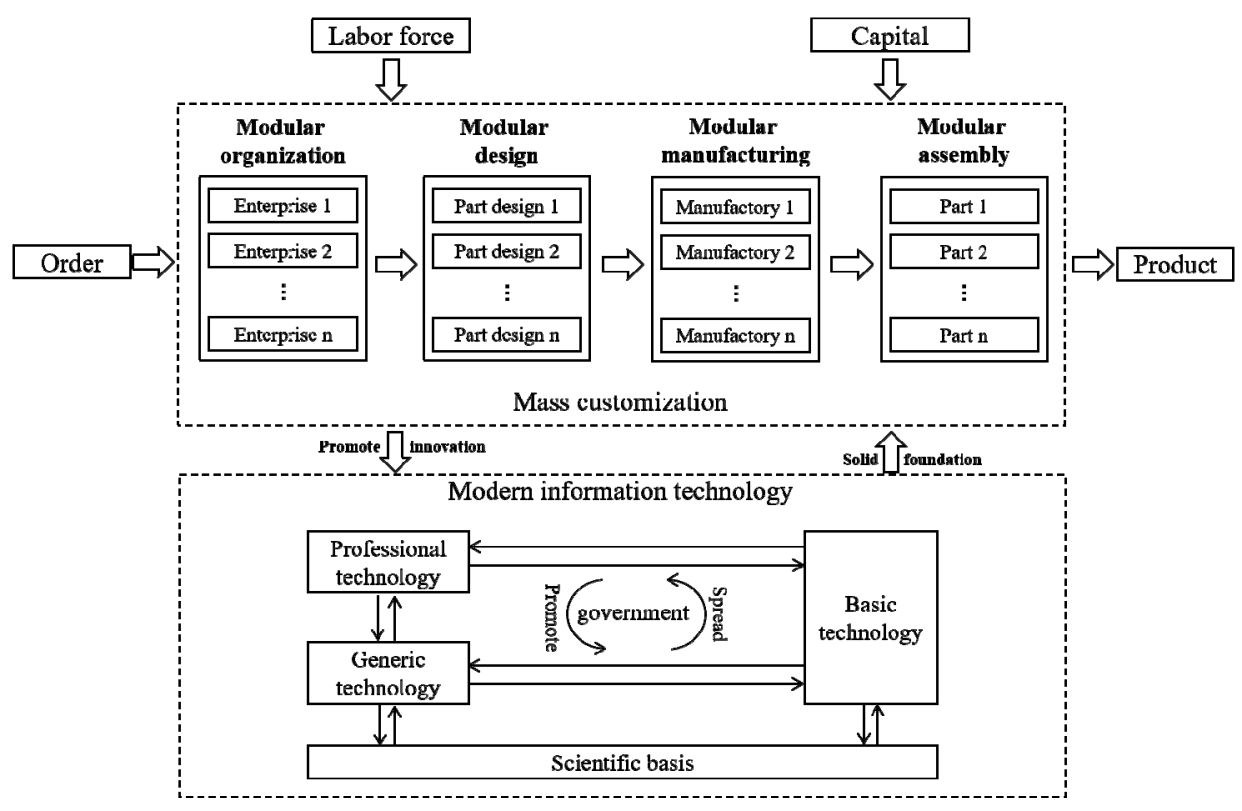

Figure 3. Hybrid modular mass customization production method under common technology 


\section{Conclusion}

This paper analyzes the key factors affecting the mass customization production model, studies the promotion of modern information technology commonality and the promotion of modular production methods on the development of mass customization, and finally forms a hybrid modular mass customization production method under common technology, as shown in Figure 3. The common transformation of modern information technology can help companies integrate market demands and develop competitive technologies and products. It can achieve the purpose of promoting the overall progress of the industry through the development of common technologies, enhancing industrial competitive advantages and promoting the development of enterprise mass customization. The hybrid modular production method utilizes the standardization and generalization of modules. It effectively combines the variability of products with the standardization of parts through modular organization, modular design, modular manufacturing, and modular assembly. Through the mass production of modules, it achieves economies of scale on the basis of meeting customer customization needs, so as to achieve the purpose of reducing the production cost of enterprise mass customization and improving the production efficiency of enterprise mass customization.

\section{Acknowledgment}

This research was financially supported by National Key Research and Development Program of China (No. 2018YFB1702900).

\section{REFERENCES}

[1] S. M. Davis, Future perfect[M]. Reading: Addison-Wesley, 1987.

[2] C. W. Hart and J. R. Taylor, Value creation through mass customization-Achieving competitive advantages through mass customization[D]. University of Michigan Business School Seminar. 1996.

[3] Y. Gao, Comparison between customized scale and mass customization[J]. Practical Electronics, 2014(20):240.

[4] A. K. Agrawal, The Impact of Investor Protection Law on Corporate Policy: Evidence from the Blue Sky Laws[J]. Journal of Financial Economics,2013, 107(2):417-435.

[5] Y. L. Zheng and R.Yi, study on the supply mode selection of generic technology from the technology chain perspective[J]. Systems Engineering-Theory \& Practice,2020,40(04):915-932. 